\title{
Diagnósticos das nascentes urbanas de Caldas Novas-GO, da bacia hidrográfica do Rio Pirapitinga, como subsídio para recuperação ambiental.
}

\author{
Wellington Rodrigues dos Santos Junior ${ }^{1}$ \\ Ilza Mara da Silva Gomes ${ }^{1}$ \\ Karla Alcione da Silva ${ }^{2}$ \\ ${ }^{1}$ Universidade Estadual de Goiás - UEG \\ Unidade Universitária de Ipameri, Anel Viário, GO 330, Km 241, Ipameri, CEP 75780- \\ 000, Goiás, Brasil \\ Email: wellingtonjunior_eng@yahoo.com.br \\ ${ }^{2}$ Secretaria Municipal do Meio Ambiente e Recursos Hídricos - SEMMARH \\ Praça do cerrado, Setor Bandeirante, Caldas Novas, CEP: 75690-000, Goiás, Brasil \\ Email: ambiente@caldasnovas.go.gov.br
}

\begin{abstract}
The urban area of Caldas Novas, driven by tourism related to the thermal waters in the region has grown wildly in recent years and many of Permanent Preservation Areas (PPA's) were replaced by new developments, farms and residences, directly affecting the springs and therefore the quality, quantity and availability of water. Because of this great human pressure on water resources, promoted by the human carelessness with the environment, this study had as main objective to diagnose the springs, urban to a later restoration work the same. Of the 33 springs evaluated in the study area, 15 of the springs were damaged, 12 were disturbed, and only 6 were in a considerable state preservation (preserved). Among these, 16 were distinguished as diffuse springs, a percentage of $48.48 \%$ and the other characterized as point springs (sources and 17 , in a percentage of $51.52 \%$ ). There was a strong correlation between the type of water tank and the degree of conservation, that is has been established that diffuse springs are more susceptible to degradation than the point.
\end{abstract}

Palavras-chaves: Nascentes urbanas; Diagnóstico ambiental; Bacia hidrográfica do rio Pirapitinga; Recuperação ambiental.

\section{1 - Introdução}

A água é um recurso natural insubstituível para a manutenção da vida, sendo assim, considerada como o mais importante dos recursos naturais por ser fundamental para os outros recursos (vegetais, animais e minerais) e por influenciar diretamente na saúde e bem estar do homem e garantir auto-suficiência econômica às regiões (PINTO et al, 2004).

A distribuição de água no mundo é desigual, sendo abundante em alguns continentes e escassas em outros (CORSON). Cerca de $10 \%$ do uso da água no mundo é para abastecimento público, $67 \%$ na agricultura e $23 \%$ na indústria. (BEI, 2002). De acordo com o relatório da Organização das Nações Unidas (ONU) a água será um recurso escasso para este milênio, e daqui a três décadas, a carência de água afetará $2 / 3$ da população mundial, o equivalente a 5,5 bilhões de pessoas (ALMEIDA et al, 2000).

O Brasil é privilegiado em relação á abundancia, possui cerca de $20 \%$ do total de água doce do planeta. Além de apresentar regiões com altos índices pluviométricos, sustentando diferentes conjuntos de vegetações. Segundo BEI, 2002, a distribuição aproximada de recursos hídricos nas regiões do país constituem cerca de $16 \%$ no Centro-Oeste, $3 \%$ no Nordeste, $68 \%$ no Norte, $6 \%$ no Sudeste e $7 \%$ no Sul.

A exploração intensa e desordenada dos recursos naturais, o uso do solo sem a utilização de técnicas conservacionistas, o desmatamento irracional e uso indiscriminado de fertilizantes 
e defensivos agrícolas vem provocando inúmeros problemas ambientais, principalmente em áreas de nascentes e de cursos d água (XAVIER e TEIXEIRA, 2007).

A quantidade e a qualidade das nascentes de uma bacia hidrográfica podem ser alteradas por diversos fatores, destacando-se, a declividade, o tipo de solo, o uso da terra, principalmente nas áreas de recarga. Assim faz-se necessário o estudo das interações dos recursos e das ações antrópicas na bacia hidrográfica (PINTO et al., 2004).

No perímetro urbano do município de Caldas Novas, encontram-se inseridos diversos cursos d água, representados por parte da bacia Hidrográfica do Rio Pirapitinga, tendo como afluente principal o Ribeirão Caldas que nasce na Serra de Caldas Novas na região Oeste do município e deságua ao Leste, na margem direita do Rio Pirapitinga. Sendo de suma importância para o abastecimento público do município, e por sua vez desemboca atualmente no lago formado pelo represamento do Rio Corumbá para a instalação da UHE Corumbá I (BIELA e CASTRO).

O Ribeirão Caldas, possui suas nascentes no Parque Estadual da Serra de Caldas Novas (PESCAN), devido a esse fato, não se tem registros de maiores problemas com relação à preservação destas. Contudo, o mesmo recebe vários contribuintes, como: Córrego-doArroizal, Córrego Capão Grosso, Córrego do Aguão, Córrego-do-bicudo, Córrego da Pontede-Terra, Córrego-do-Açude e outros cursos hídricos que nascem dentro da área urbana de Caldas Novas, sendo que em quase sua totalidade as nascentes destes contribuintes encontram-se sem nenhum processo de preservação, e vêm sofrendo com o crescimento da área urbana do município (SANTOS JUNIOR et al., 2009).

A área urbana de Caldas Novas, impulsionada pelo turismo relacionado às águas termais da região, vem crescendo desordenadamente, e muitas Áreas de Preservação Permanente (APP's) foram substituídas por empreendimentos, chácaras e residências, afetando diretamente as nascentes e conseqüentemente a qualidade, quantidade e disponibilidade de água. Diante dessa situação o estudo foi desenvolvido visando fazer um diagnóstico ambiental das nascentes urbanas de Caldas Novas e consequentemente fornecer dados e subsídios necessários para um possível projeto de recuperação que será implantado juntamente com a Prefeitura Municipal de Caldas Novas e a Secretaria Municipal do Meio Ambiente e Recursos Hídricos (SEMMARH).

\section{2 - Objetivos}

Realizar a análise do grau de conservação das nascentes urbanas, com o intuito de levantar áreas críticas, visando à manutenção das mesmas e conseqüentemente da qualidade da água, considerando-as como condições básicas para o sucesso do planejamento da conservação e proteção da qualidade dos mananciais hídricos. Sendo assim o objetivo desse estudo foi avaliar o estado de conservação das nascentes urbanas de Caldas Novas, para indicar suas condições ambientais, se tornando portanto, uma ferramenta que auxiliará futuros programas de recuperação ambiental dessas nascentes.

\section{3 - Material e Métodos}

O estudo foi realizado em toda a área urbana do município de Caldas Novas, localizada na região sudeste do estado de Goiás, compreendida pelas seguintes coordenadas geográficas: $17^{\circ} 43^{\prime} 31,00^{\prime \prime}$ de latitude Sul e $48^{\circ} 36^{\prime} 37,00^{\prime \prime}$ de longitude Oeste, com sua altitude variando entre 520 e 1043 metros, distando a aproximadamente $180 \mathrm{~km}$ de Goiânia, capital do Estado conforme Figura 1. 


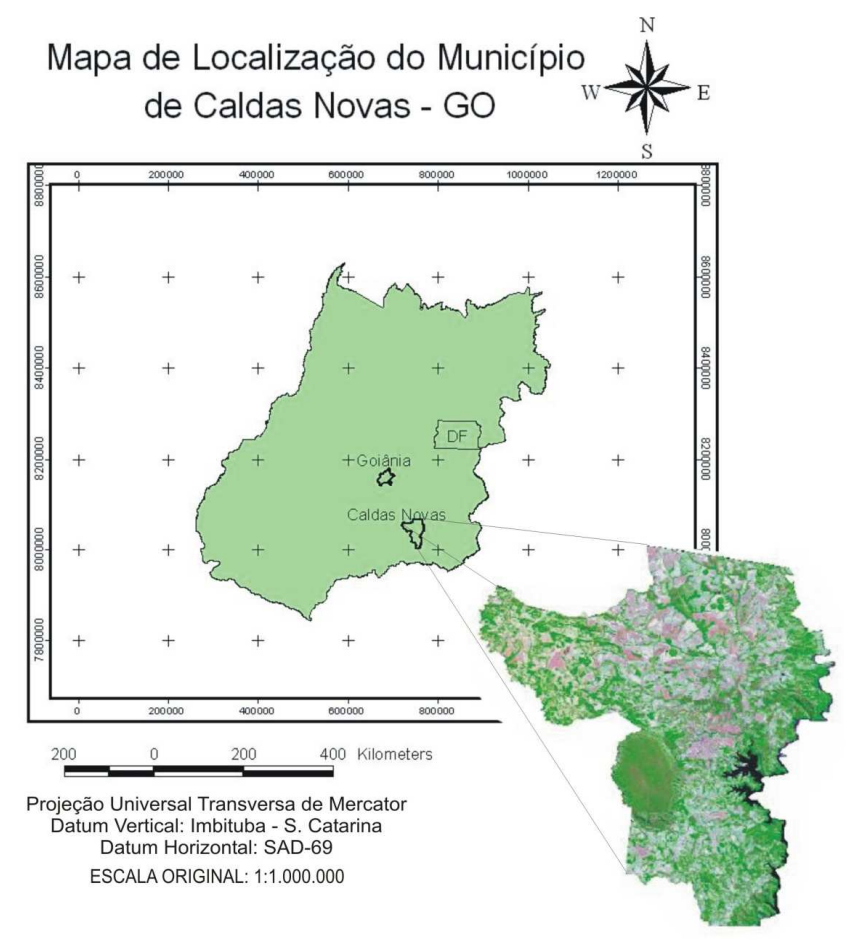

Figura 1: Imagem e mapa de localização do Município de Caldas Novas, no Estado de Goiás.

O clima regional é o "tropical continental" (Aw, segundo a classificação de Köeppen), com chuvas de verão (tropical chuvoso de savana) e estação seca de abril a outubro. A temperatura média anual é de $20,5^{\circ} \mathrm{C}$ e a umidade relativa do ar varia de $45 \%$ na seca a $85 \%$ nos meses úmidos. (Furnas Centrais Elétricas S.A. Sondotécnica S.A., 1989).

Para realização do projeto, foi considerado como nascente, cada inicio de tributário em área urbana do município de Caldas Novas, beneficiando ou não a uma fonte de água de acúmulo (represa), ou quaisquer corpo d'água, pois algumas das nascentes estudadas não formam contribuintes, por estarem situadas em locais como ruas, calçadas, terrenos baldios e até mesmo quintais de residências e escoam superficialmente não alimentando nenhuma rede de drenagem.

Durante o trabalho de campo foram obtidas todas as coordenadas geográficas das nascentes utilizando GPS, modelo Garmim etrex e o programa GPS TrackMaker ${ }^{\circledR}$, para posterior identificação dessas coordenadas. A localização de cada nascente foi realizada com auxílio de imagens de satélite, mapa planialtimétrico da cidade de Caldas Novas fornecido pela SEMMARH (Secretaria Municipal do Meio Ambiente e Recursos Hídricos) e mapa digital do SIG Goiás realizado pela secretaria de Indústria e comercio do estado de Goiás (SIC) e superintendência de geologia e mineração (SGM), aliados as informações fornecidas a partir de entrevistas com moradores locais e técnicos da Secretaria Municipal do Meio Ambiente e Recursos Hídricos. Os dados digitais foram visualizados e editados no software SPRING versão 5.0.5.

As nascentes foram classificadas em pontuais ou difusas, de acordo com o tipo de reservatório que estão associadas, isto é, como os lençóis freáticos dão origem às nascentes. Foram classificadas como nascentes pontuais aquelas que apresentam ocorrência de fluxo d água em apenas um único ponto do terreno. As nascentes foram classificadas como difusas 
quando não havia um único ponto de vazão definido no terreno, apresentando vários olhos d água (PINTO et al, 2004).

A metodologia adotada para diagnosticar a situação ambiental das nascentes, foi obtida a partir da avaliação do grau de conservação das mesmas, semelhante à proposta por Pinto et al (2004) com algumas adequações, onde a vegetação em torno das nascentes foram demarcadas em 4 quadrantes e medidas com uma trena em um raio de cinqüenta metros, onde avaliou-se a vegetação situada acima, abaixo, à direita e à esquerda representadas pelas áreas de preservação permanente, conforme estabelecido pela Lei $n^{\circ}$. 4.771, de 1965 que institui o Código Florestal Brasileiro. Diante dessa análise as nascentes foram classificadas em três categorias de conservação:

-Preservadas, quando apresentavam pelo menos 50 metros de vegetação natural no seu entorno medidas a partir do olho d'água em nascentes pontuais ou a partir do olho d'água principal em nascentes difusas;

-Perturbadas, quando não apresentavam 50 metros de vegetação natural no seu entorno, mas apresentavam bom estado de conservação.

-Degradadas, quando se encontravam com alto grau de perturbação, muito pouco vegetadas, solo compactado, com presença de processos erosivos, resíduos sólidos, esgotos domésticos ou industriais, lixos e entulhos e em locais edificados com construções consolidadas.

Todas as nascentes situadas na zona urbana de Caldas Novas, abarcada em uma área de aproximadamente $270 \mathrm{Km}^{2}$ foram visitadas e analisadas, registrando-se um total de 33 nascentes que abastecem 5 córregos, dentre as difusas e pontuais, todas inseridas na bacia hidrográfica do rio Pirapitinga. Esse estudo de campo ocorreu nos meses de Dezembro de 2008 à Agosto de 2009.

\section{4 - Resultados e Discussão}

Foram contabilizadas 14 nascentes intermitentes e 19 nascentes perenes, totalizando 33 nascentes urbanas em Caldas Novas, porém, segundo informações da Secretaria Municipal do Meio Ambiente e Recursos Hídricos e de moradores, três delas deixaram de existir, devido à elevada ação antrópica favorecendo a total degradação.

Das 33 nascentes avaliadas na área de estudo, 15 das nascentes encontravam-se degradadas, 12 encontravam-se perturbadas, e apenas 6 encontravam-se em estado preservação considerável (preservada). Dentre essas, 16 distinguem-se como nascentes difusas, em um percentual de $48,48 \%$ (tabela 1) e as demais caracterizadas como pontuais (sendo 17 nascentes, em um percentual de 51,52\%). Houve uma forte correlação entre o tipo de reservatório de água e o grau de conservação, isto é foi verificado que as nascentes difusas são mais propícias á degradação do que as pontuais.

Tabela 1: classificação das nascentes quanto ao grau de conservação e quanto ao tipo de reservatório de água no afloramento. 


\begin{tabular}{lcccccccc}
\hline \multicolumn{1}{c}{ Classificação } \\
\hline Tipo & Degradadas & \multicolumn{2}{c}{ Perturbadas } & \multicolumn{2}{c}{ Preservadas } & \multicolumn{2}{c}{ Total } \\
\hline Pontual & Qtde & $\%$ & Qtde & $\%$ & Qtde & $\%$ & Qtde & $\%$ \\
\hline Difusa & 5 & 15,15 & 7 & 21,21 & 5 & 15,15 & 17 & 51,51 \\
\hline Total & 10 & 30,30 & 5 & 15,15 & 1 & 3,03 & 16 & 48,48 \\
\hline
\end{tabular}

Como conseqüência da área de estudo está localizada no perímetro urbano, as perturbações encontradas nas nascentes são em sua maioria originadas pela intervenção antrópica, com implantação de empreendimentos de diversas naturezas, como loteamentos, instalação de pequenas indústrias, construção de casas e chácaras, lançamento de lixo doméstico e industrial e criação de animais domésticos. Outro fator agravante observado no estudo está relacionado às nascentes localizadas em vias públicas e calçadas, como conseqüência de problemas no planejamento urbano e social, favorecendo o transbordamento de fossas sanitárias, devido excesso de água proveniente da proximidade com os afloramentos.

\section{5 - Conclusão}

Verificou-se que das 33 nascentes urbanas de Caldas Novas apenas 6 encontra-se preservada, encontrando-se em sua maioria degradadas. Essa situação é alarmante, pois em algumas áreas ainda oferecem subsídios necessário para a instalação imediata de um projeto de recuperação (nascentes perturbadas), mas outras seriam necessárias a adoção de medidas drásticas como a retirada de qualquer intervenção antrópica, o que é praticamente inviável considerando que essas áreas são em sua maioria ocupadas por residências e outros empreendimentos. Esse processo de degradação acentuado mostra a forte pressão antrópica sobre essas áreas devido à ausência de planejamento ambiental e urbanização desordenada.

Levando em consideração a situação supracitada, torna-se necessário o desenvolvimento de estudos aprofundados em relação às nascentes urbanas de Caldas Novas, e uma análise sistemática dessa situação pelos órgãos responsáveis por promover a adequação ambiental dessas áreas, pois além de estarem incluídas como áreas de preservação permanente do Bioma Cerrado, existe a importância da cidade no cenário do turismo nacional, que merece ter seus mananciais hídricos conservados.

\section{6 - Referências Bibliográficas}

ALMEIDA, D. S.; DUARTE, A. J.; ARAÚJO, R. P. Projeto de recuperação de matas ciliares e nascentes da bacia do Rio dos Mangues. In: CONGRESSO DE EXPOSIÇÃO INTERNACIONAL SOBRE FLORESTAS, 6, 2000, Porto Seguro. Anais... Rio de Janeiro, 2000. p. 575-576.

BEI. 2002. Como cuidar do seu meio ambiente. Editora Bei Comunicação, São Paulo. 272.

BIELLA, C. A.; COSTA, R. A. ANÁLISE DA QUALIDADE AMBIENTAL DAS NASCENTES URBANAS DE CALDAS NOVAS - GO. Disponível em <http://200.199.231.226/portal/publicacao/arqprof/artigo2.pdf $>$. Acesso em 15 de agosto de 2009.

CORSON, W. H. 2002. Manual global de ecologia. Editora Augustus, São Paulo. $4^{\circ}$ edição. 413.

FURNAS CENTRAIS ELÉTRICAS S.A.; SONDOTÉCNICA S.A. Estudos de avaliação de impacto ambiental EIA. Rio de Janeiro, 1989. (Relatório). biomass and structure of phytoplankton in large rivers. Arch. Hydrobiol. Suppl., Stuttgart, v. 113, no.1-4, p.161-187. 
PINTO, L. V. A.; BOTELHO, S. A.; DAVIDE, A. C.; FERREIRA, E. Estudo das nascentes da bacia hidrográfica do Ribeirão Santa Cruz, Lavras, MG. Scientia Forestalis, n. 65, p. 197-206, 2004.

SANTOS JUNIOR, W. R.; GOMES, I. M. S.; CAVA, M. G. B. Análise do grau de conservação das nascentes urbanas de Caldas Novas - GO. In: $9^{\circ}$ CEB - Congresso de Ecologia do Brasil. Anais... SEB. São Lourenço. 2009.

XAVIER, A. L.; TEIXEIRA, D. A. Diagnóstico das nascentes da sub-bacia hidrográfica do Rio São João em Itaúna, MG. In: CONGRESSO DE ECOLOGIA DO BRASIL, 8., 2007, Caxambu. Anais... Caxambu, 2007. 